\title{
Embolic stroke complicating Staphylococcus aureus endocarditis circumstantially linked to rectal trauma from foreign body: a first
}

\section{case report}

\author{
Braj B Pandey*, Tuan C Dang and John F Healy
}

Address: University of California, San Diego, USA

Email: Braj B Pandey* - braj.pandey@med.va.gov; Tuan C Dang - tuan.dang@med.va.gov; John F Healy - jfhealy@ucsd.edu

* Corresponding author

Published: 27 May 2005

BMC Infectious Diseases 2005, 5:42 doi:10.1 186/147/-2334-5-42

This article is available from: http://www.biomedcentral.com/I47I-2334/5/42

(C) 2005 Pandey et al; licensee BioMed Central Ltd.

This is an Open Access article distributed under the terms of the Creative Commons Attribution License (http://creativecommons.org/licenses/by/2.0), which permits unrestricted use, distribution, and reproduction in any medium, provided the original work is properly cited.

\begin{abstract}
Background: Diagnostic and therapeutic instrumentation of the lower gastrointestinal tract has been reported to result in bacteremia and endocarditis. No such case has been reported in persons with a history of rectal foreign body insertion despite its potential for greater trauma.
\end{abstract}

Case presentation: A 58-year-old male was admitted with confusion and inability to speak. His past history was notable for hospitalization to extract a retained plastic soda bottle from the rectosigmoid two years prior. On examination, he was febrile, tachycardic and hypotensive. There was an apical pansystolic murmur on cardiac examination. He had a mixed receptive and expressive aphasia, and a right hemiparesis. On rectal examination he had perianal erythema and diminished sphincter tone. Magnetic resonance imaging of the brain showed infarction of the occipital and frontal lobes. Transesophageal Echocardiography of the heart revealed vegetations on the mitral valve. All of his blood culture bottles grew methicillin sensitive Staphylococcus aureus. He was successfully treated for bacterial endocarditis with intravenous nafcillin and gentamicin. The rectum is frequently colonized by Staphylococcus aureus and trauma to its mucosa can lead to bacteremia and endocarditis with this organism.

In the absence of corroborative evidence such as presented here, it is difficult to make a correlation between staphylococcal endocarditis and anorectal foreign body insertion due to patients being less than forthcoming

Conclusion: There is a potential risk of staphylococcal bacteremia and endocarditis with rectal foreign body insertion. Further studies are needed to explore this finding. Detailed sexual history and patient counseling should be made a part of routine primary care.

\section{Background}

There is a large body of surgical literature reporting anal eroticism resulting in rectal trauma and retained foreign bodies $[1,2]$, but there is no report of bacteremia or endocarditis occurring in these patients. Staphylococcus aureus is an aggressive pathogen and bacteremia with this organ- ism can infect healthy heart valves. The rectal mucosa is a major site of colonization by this organism. We describe a patient with a past history of surgical extraction of a retained plastic soda bottle from the rectosigmoid, who later developed staphylococcal endocarditis resulting in 


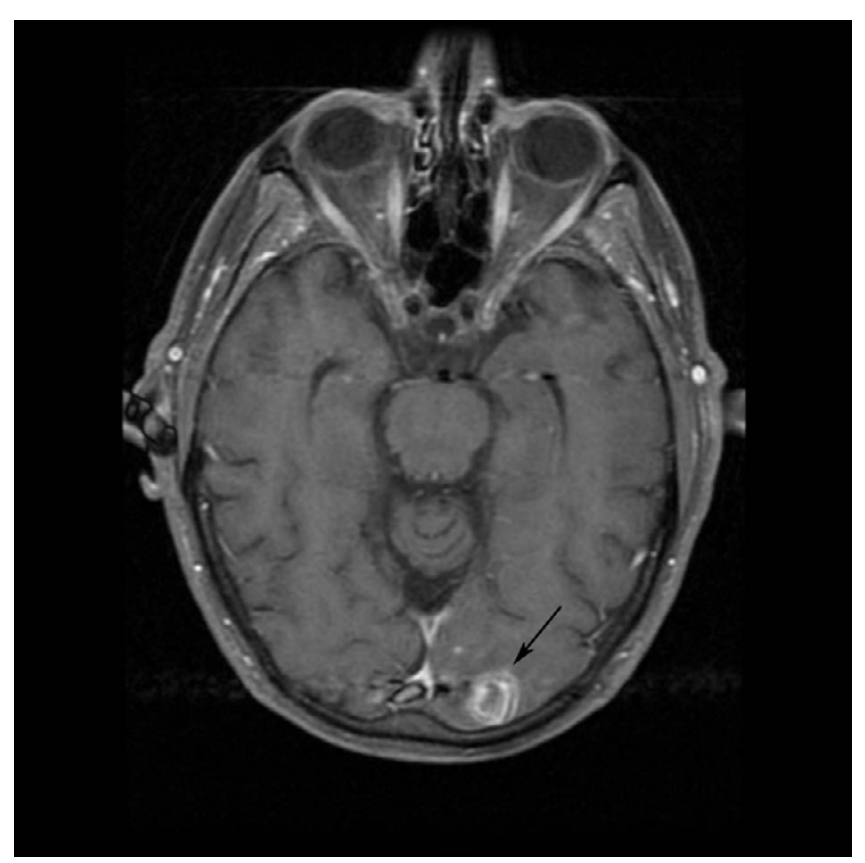

Figure I

Contrast enhancing infarction in occipital lobe (arrow)

septic embolism and stroke. No such case has been reported in the literature.

\section{Case presentation}

A 58-year-old male was brought to the emergency room with confusion and an inability to speak for 1 day. He had a past history of hypertension and hypomania. He was single and he lived alone. On physical examination, his blood pressure was $80 / 63 \mathrm{~mm}$ of $\mathrm{Hg}$, heart rate $126 /$ minute, and temperature $102^{\circ} \mathrm{F}$. He was awake but unable to speak due to a mixed receptive and expressive aphasia. He had right homonymous hemianopsia and hemiplegia. Cardiac examination was positive for a pansystolic murmur in the apical area. The abdominal examination was unremarkable. On rectal examination there was perianal erythema and diminished sphincter tone. Complete blood count showed WBC $15,400 / \mathrm{mm}^{3}$ with a left shift, hematocrit $49 \%$, and normal platelets. Serum chemistries showed glucose $84 \mathrm{mg} / \mathrm{dl}$, albumin $2.9 \mathrm{mg} / \mathrm{dl}$, and calcium $8.5 \mathrm{mg} / \mathrm{dl}$. Magnetic Resonance Imaging of the brain, including diffusion weighted imaging, revealed acute hemorrhagic infarction of the left occipital lobe and acute embolic infarctions of the left frontal and right occipital lobes (Fig 1 and 2). Transesophageal Echocardiogram demonstrated mitral regurgitation and large vegetations on the posterior leaf of the mitral valve. Splenic and renal infarcts were visible on Computerized Tomography of the abdomen. All of the blood culture bottles and the urine culture grew methicillin sensitive Staphylococcus aureus. Treatment of the bacterial endocarditis was started with intravenous nafcillin and gentamicin. The patient had a significant recovery of speech and motor function within a few days. When asked about recent dental work, he gave a history of a tooth extraction 2-3 days before the hospitalization but was unable to provide information about his dentist. A dentist from the hospital examined the patient and found no clinical evidence of the extraction. The patient underwent a complete neuropsychiatric evaluation. He displayed confabulation and perseverance (marriage, retirement, hospitalization were reported using the same date which was his birthday). He also had significant executive dysfunction including concrete thinking and poor insight regarding his health and cognitive problems. On hospital day 12 the patient had mitral valve replacement surgery using a bioprosthetic valve. He completed a six-week course of intravenous antibiotic treatment. He also underwent extensive rehabilitation therapy and was sent home after 8 weeks of hospitalization. On subsequent follow-up visits the patient showed complete recovery from the stroke and was back to his baseline. In response to questions about his sexual history the patient indicated having heterosexual relations with multiple partners. However, his answers were inconsistent and seemed unreliable.

A closer examination of his medical records revealed that two years prior to this hospitalization, the patient was admitted with a plastic soda bottle retained in the rectosigmoid for 3 days. The bottle had been filled with warm water and inserted into his anal canal for sexual stimulation. It slipped all the way into the rectum and could not be retrieved. His attempts to extract it at home were unsuccessful. In the emergency room his physical examination was normal except for a palpable mass in the suprapubic area, decreased anal sphincter tone and a dilated rectal vault. On X-ray of the abdomen, the outline of a plastic bottle was visible in the rectosigmoid (Fig 3 ). The patient was taken to the operating room and under spinal anesthesia the bottle was extracted. He had multiple lacerations of the rectal mucosa but there was no perforation. He went home the next day. On follow-up visits to primary care he was noted to be overall healthy except having mild hypertension. His behavior was indicative of hypomania, but he did not get a formal psychiatric evaluation.

Foreign bodies in the rectum and methods of their extraction have been amply chronicled in the surgical literature [1]. Sexual stimulation is the reason in a majority of these cases [2]. Local trauma, perforation, and resultant peritonitis are well known complications [3]. An unlimited PUBMED search for articles on bacteremia or endocarditis related to rectal foreign body insertion was unfruitful (We 


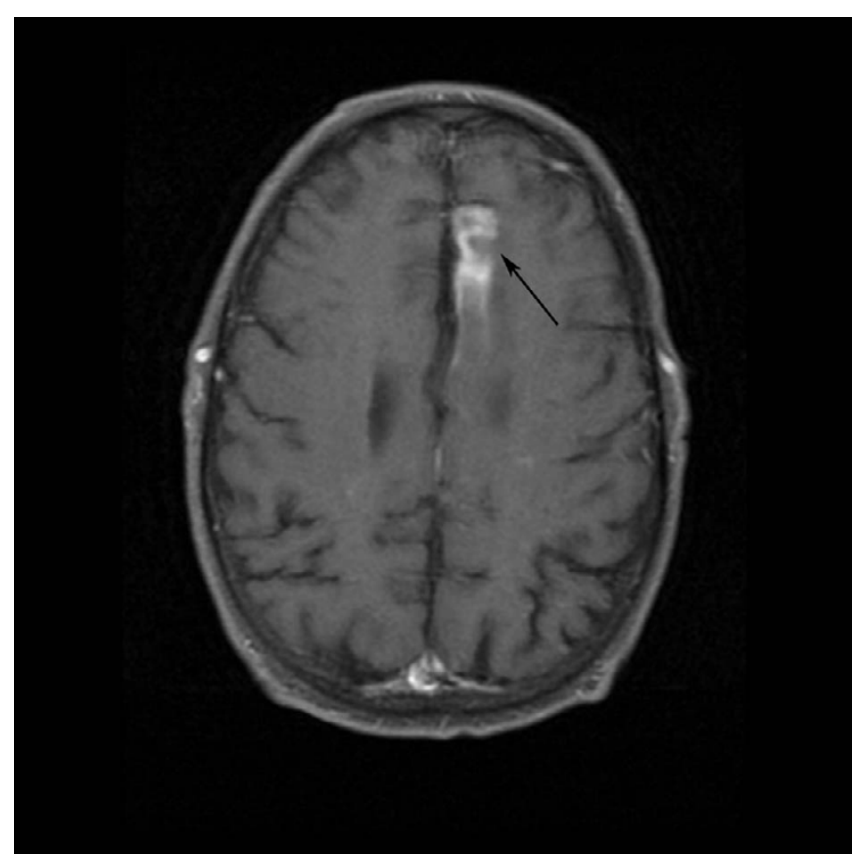

Figure 2

Contrast enhancing infarction in the frontal lobe (arrow).

tried MeSH terms anal/rectal/colorectal/foreign bodies/ anorectal /sexual deviation for the purpose). Bacteremia and septicemia from barium enema [4], and therapeutic anal dilatation [5] have been published. Procedures like fiberoptic sigmoidoscopy are known to cause endocarditis [6], but septic stroke resulting from endocarditis related to lower gastrointestinal instrumentation has also not been reported.

The patient's history of anorectal insertion of a plastic soda bottle for sexual gratification is consistent with published reports of use of large objects for this purpose [7]. The resultant rectal trauma can easily lead to bacteremia. Rectal carriage of Staphylococcus aureus is well documented and is a potential source of infection [8]. This organism tends to be more abundant on the rectal mucosa than within the feces [9]. In a study of gastrointestinal colonization, Staphylococcus aureus grew from the culture of rectal swabs in $60 \%$ cases versus $53 \%$ positive culture of nasal swabs taken from the same subjects [10]. This organism is known to cause endocarditis of normal heart valves $[11,12]$. Neurologic complications of infective endocarditis, particularly embolic events, tend to be higher in cases of endocarditis caused by Staphylococcus aureus [13].

It is known that few patients with rectal foreign bodies will freely admit to transanal introduction [14]. This

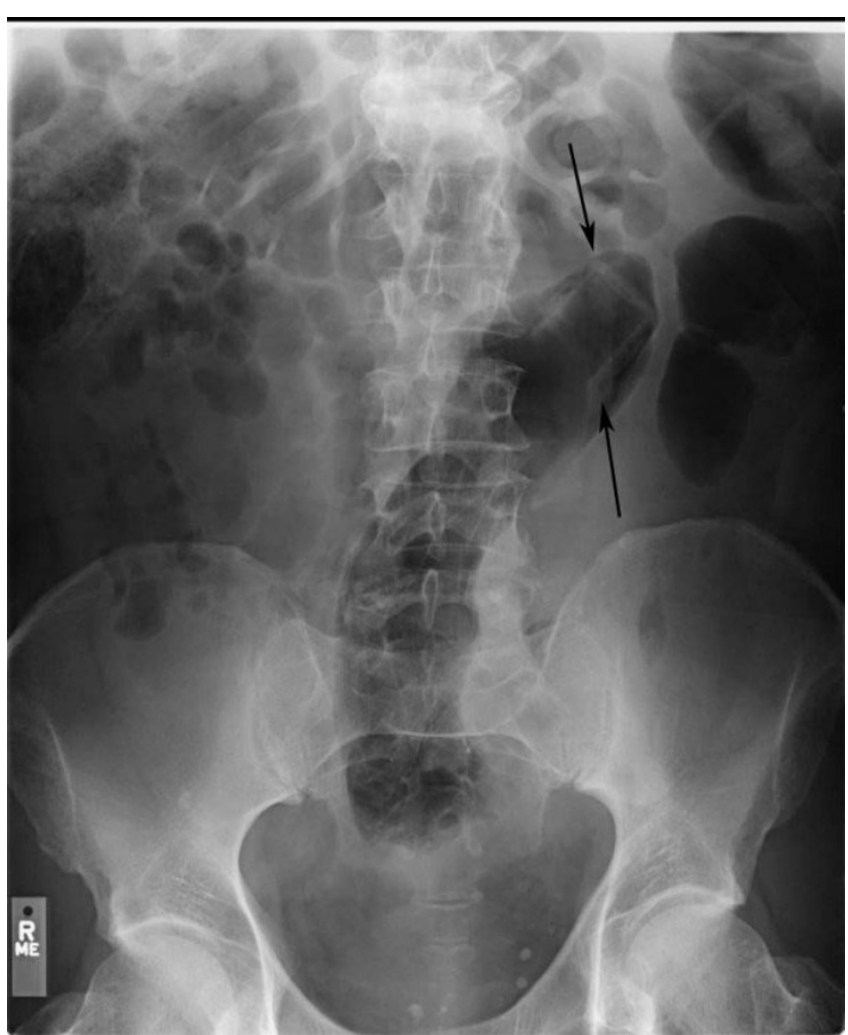

Figure 3

X-ray of abdomen 2 years prior showing outline of plastic soda bottle in sigmoid colon (arrows).

explains to some extent the paucity of literature linking this practice with bacteremia or endocarditis. We believe our patient was habituated to rectal insertion of foreign bodies and that is evident from his previous history along with the clinical findings of perianal erythema and diminished sphincter tone [14]. In the absence of a reliable history from the patient, the link between endocarditis and rectal trauma in this case is based on circumstantial evidence. A further study of patients with well-documented evidence of rectal foreign body insertion could be the next step to explore this important observation.

\section{Conclusion}

The rectum is a frequent site of Staphylococcus aureus carriage. Trauma from foreign objects in the rectum carries a risk of staphylococcal bacteremia that is known to result in endocarditis of both normal and abnormal heart valves. Further studies are needed to explore this finding. It is important to get a detailed sexual history from patients visiting primary care clinics. Patient education and warning may help prevent catastrophic complications of this risky practice. 


\section{Competing interests}

The author(s) declare that they have no competing interests.

\section{Authors' contributions}

BBP carried out the clinical study of the patient, conceived the study, researched the literature, and wrote the article. TCD carried out the clinical study of the patient, researched the literature, and edited the article. JFH provided radiological diagnosis, figure legends and computerized figures.

\section{Acknowledgements}

Claudia Hall, NP for providing additional clinical information.

A written consent was obtained from the patient for publication of study.

\section{References}

I. Yaman M, Deitel M, Burul C], Shahai B, Hadar B: Foreign bodies in the rectum. Can J Surg 1993, 36:173-7.

2. Cohen JS, Sackier JM: Management of colorectal foreign bodies. J R Coll Surg Edinb 1996, 4I:3। 2-5.

3. Barone JE, Sohn N, Nealon TF Jr: Perforations and foreign bodies of the rectum: report of 28 cases. Ann Surg 1976, 184:601-4.

4. Williams SM, Harned RK: Recognition and prevention of barium enema complications. Curr Probl Diagn Radiol I99|, 20:|23-5I.

5. Goldman G, Zilberman M, Werbin N: Bacteremia in anal dilatation. Dis Colon Rectum 1986, 29:304-5.

6. Norfleet RG: Infectious endocarditis after fiberoptic sigmoidoscopy. With a literature review. J Clin Gastroenterol I991, | 3:448-45 |.

7. Subbotin VM, Davidov MI, Fainshtein AV, Abdrashitov RR, Rylov luL, Sholin NV: Foreign bodies of the rectum. Vestn Khir Im I I Grek 2000, I 59:91-95.

8. Williams REO: Healthy carriage of Staphylococcus aureus: its prevalence and importance. Bacteriol Rev 1963, 27:56-71.

9. Kent C, Solliday J: Comparision of rectal swabs and stool cultures for the detection of gastrointestinal carriage of Staphylococcus aureus. Journal of Clinical Microbiology 1980, I I :433-434.

10. Rimland D, Roberson B: Gastrointestinal carriage of methicillin-resistant staphylococcus aureus. Journal of Clinical Microbiology 1986, 24: I37-138.

II. Petti CA, Fowler VG Jr: Staphylococcus aureus bacteremia and endocarditis. Cardiol Clin 2003, 2 I:219-233.

12. Barrau K, Boulamery A, Imbert G, Casalta JP, Habib G, Messana T, Bonnet JL, Rubinstein E, Raoult D: Causative organisms of infective endocarditis according to host status. Clin Microbiol Infect 2004, I 0:302-308.

13. Tunkel AR, Kaye D: Neurologic complications of infective endocarditis. Neurol Clin 1993, I I:4 19-40.

14. Ooi BS, Ho YH, Eu KW, Nyam D, Leong A, Seow-Choen F: Management of anorectal foreign bodies: a cause of obscure anal pain. Aust N ZJ Surg 1998, 68:852-855.

\section{Pre-publication history}

The pre-publication history for this paper can be accessed here:

http://www.biomedcentral.com/1471-2334/5/42/prepub
Publish with Bio Med Central and every scientist can read your work free of charge

"BioMed Central will be the most significant development for disseminating the results of biomedical research in our lifetime. "

Sir Paul Nurse, Cancer Research UK

Your research papers will be:

- available free of charge to the entire biomedical community

- peer reviewed and published immediately upon acceptance

- cited in PubMed and archived on PubMed Central

- yours - you keep the copyright

Submit your manuscript here:

http://www.biomedcentral.com/info/publishing_adv.asp
BioMedcentral 